\title{
Relationship between self-rated health and depression risk among children: Promoting school-medical care cooperation for child suicide prevention
}

Michiyo Okada ( $\square$ mic-okada@kochi-u.ac.jp )

Kochi University: Kochi Daigaku

Yoshihiro Nakadoi

Shikoku Medical Center for Children and Adults

Ai Fujikawa

Takamatsu City Public Health Center

Research article

Keywords: physical health, mental health, self-rated health, child and adolescent depression, suicide, cooperation

Posted Date: July 9th, 2021

DOI: https://doi.org/10.21203/rs.3.rs-676382/v1

License: (9) (1) This work is licensed under a Creative Commons Attribution 4.0 International License. Read Full License 


\section{Abstract \\ Background}

Japan is facing a markedly high incidence of adolescent suicide. This study examines the relationship between depression and selfrated health, which is a significant factor driving people toward suicide, highlighting the importance of children's assessments of their health.

\section{Methods}

In this cross-sectional study, an original questionnaire combining text and illustrations was administered to 6,421 elementary, junior, and senior high school students. To assess children's self-rated health, we classified the survey questions into two domains: physical and mental health. We further classified the questions based on symptom duration. Depression assessment was based on the Depression Self-Rating Scale for Children. To provide a basis for the effective use of the self-rated health assessment tool, we classified the respondents into three groups based on physical/mental conditions together with the duration of those conditions and made comparisons. The groups were Favorable Health, Temporarily Poor Health, and Persistently Poor Health, and the results were analyzed using an ANOVA.

\section{Results}

Self-rated health levels decreased, and depressive conditions worsened with age. Although most children led physically and mentally healthy school lives, the mean Depression Self-Rating Scale score was significantly higher for the Persistently Poor Health group than the other two, and the Temporarily Poor Health group scored significantly higher than the Favorable Health group for both physical and mental health (all $p<0.001$ ).

\section{Conclusions}

As the Temporarily and Persistently Poor Health groups in the domains of physical and mental health are more likely to be depressed, timely cooperation between schools and medical institutions is imperative to prevent depression.

\section{Background}

Japan is experiencing increasingly high rates of suicide among young people. It is the only developed country where suicide is the leading cause of death for those aged $15-34$, and the frequency of incidents of adolescent suicide is particularly high [1]. Data clarifying the causes of suicide are often unavailable for the 10-14 age group, but depression is frequently reported to be a major contributing factor among senior high school students. Specifically, the incidence of suicide associated with depression or other mental health disorders is high among female senior high school students [1]. Although Japan is implementing nationwide suicide prevention measures, discussions to prevent adolescent suicide remain insufficient.

Self-rated health is an index to subjectively assess one's health condition; it aids in examining overall health conditions that are difficult to identify with objective parameters, such as death and prevalence rates. In Europe and the United States, this is known as "subjective health" or "self-reported health." Self-rated health was incorporated into the National Health Interview Survey in the United States in 1972. In Japan, it was first used in the Comprehensive Survey of Living Conditions in 1986 and has since been examined in many social surveys [2]. Self-rated health is often examined in combination with lifestyle, quality of life, and physical symptoms. Many studies involving older adults report higher survival rates for individuals with higher self-rated health levels, revealing their influence on vital prognoses [3, 4]. Used for autonomous health assessment and accurate representation of lifestyles and related physical health conditions, self-rated health is an excellent assessment and support tool that may facilitate bidirectional health support [5]. It is also a simple test that is utilized as an alternative index when objective health assessment through medical examinations is difficult [6]. However, existing studies have only investigated adults. A pilot survey involving elementary and junior high school students and teachers is the only reported study on self-rated child health [7]. 
A previous study of young people examining the risk of suicide based on suicidal behavior and protective factors revealed that mental health disorders increase suicide risk, as they were present in many adolescents who had committed or attempted suicide [8]. In a Japanese survey involving adolescents aged 13-18 with a history of suicide attempts, health problems, mainly those related to mental health disorders, were the leading contributing factors to these attempts [9]. A study investigating cases of suicide among those under 15 over the past decade in New Zealand showed that suicide risk increased with age and mental health problems were noted in many cases [10]. Depression was reported to be the psychiatric risk factor most significantly correlated with adolescent suicide [11, 12]. A Finnish study comparing males and females who died by suicide between the ages of 13 and 22, showed that mood disorders were present in $68 \%$ of females [13]. Another Finnish study showed that mental health disorders were present in $94 \%$ of all suicide cases among those aged $13-19$, and there was a strong correlation between adolescent suicide and depression [14]. A survey investigating suicide among individuals under 20 in New York City revealed that the presence of substance-related disorders, represented by alcoholism, and concomitant mood disorder, which was the main risk factor in both sexes, also increased the risk of suicide [15]. Harrington [16] conducted an epidemiological study reporting that depressive states lead to depression in children, and the prevalence of these states rapidly and markedly increases during adolescence. Murata et al. [17] noted that depressive states among students were closely associated with problems related to the education system or school structure. Students in depressive states often go through a process where their self-expectations and ideals are unmet and their self-worth gradually decreases [17, 18]. Thus, depressive states may be a strong trigger for suicide attempts.

According to a report from Norway, suicidal ideation and trigger events are less clear in suicide during early adolescence (under 15) than in late adolescence (aged 15 or over) [19]. Similarly, in Japan, data that would facilitate the identification of causes or motives are unavailable in many cases of suicide among those aged $10-14$ [1]. Having analyzed the risk factors associated with suicide among young people over the past 10 years, one study concluded that these factors are explained mainly by psychiatric problems during adolescence; therefore, it is necessary to identify protective factors for suicidal behavior and screen for increased risk of suicide in children [20]. In addition to such screening, curricula [21] and acknowledge-care-tell approaches to detect such risks were reported to be important for suicide prevention [22]. In Japan, in accordance with the Ministry of Education, Culture, Sports, Science and Technology's initiative [23], which highlights the need to review the managers' leadership, the ideal way of school affairs, and the way faculty and staff work so that they can collaborate as a team by using their diverse expertise, some schools are trying to connect needy students to medical care after a comprehensive physical and mental health examination by the school nurse. However, as it is a labor- and time-intensive task, if schools could confidently and reliably connect to medical care through simple screening tests, they would be able to save many children.

Based on these perspectives, for the prevention of suicide among young people, this study aims to: 1) analyze children's self-rated health status, 2) analyze the association between self-rated health and depressive states that frequently lead to suicide, and 3 ) propose the effective use of a self-rated health assessment tool to connect educational institutions to medical care for early suicide prevention intervention.

\section{Methods}

\section{Participants}

We selected schools located in seven cities in A, B, and C prefectures in Japan, each with a population of 30,000. We believe these were the most representative schools in Japan with regard to school courses, scale, student sex ratio, and academic ability. A questionnaire survey was conducted with a total of 6,421 (3,262 male, 3,159 female) students: 1,962 (1,031 male, 931 female) from four elementary schools, 2,097 (1,079 male, 1,018 female) from five junior high schools, and 2,362 (1,152 male, 1,210 female) from four senior high schools. Subsequently, responses from 5,641 students (2,824 male, 2,817 female), of whom 1,592 (830 male, 762 female) belonged to elementary schools, 1,875 (958 male, 917 female) to junior high schools, and 2,174 (1,036 male, 1,138 female) to senior high schools, who were present on the day of the survey and completed the entire questionnaire correctly, were analyzed (valid response rate: $87.9 \%$ ).

\section{Study period and procedure}

A period between late November 2018 and early June 2019, when neither in-school events nor regular tests took place, was chosen for each school. The survey was conducted during a short morning homeroom session or at lunchtime by homeroom teachers and 
their assistants on a school-wide basis.

\section{Study items}

To assess self-rated health, the Comprehensive Survey of Living Conditions presents the following question: "What is your current health condition? Please mark the most appropriate number with a circle," with response options of "1: Good," "2: Relatively good," "3: Normal," "4: Relatively bad," and "5: Bad." Answers were quantified by scoring "Good" as 5 and "Bad" as 1. However, solely textual response options may not be easy for children, especially elementary school students, to understand. Therefore, upon deliberation, we created original questions by combining words and illustrations that utilized the concept of weather to facilitate understanding (Figs. 1 and 2).

[Figures 1 and 2 around here]

Additionally, considering the necessity of asking about physical health symptoms such as recurring headaches, abdominal pain, and vomiting [24-27], along with mental health symptoms, we classified these questions into two domains and presented them separately, as follows: "If your body were the weather, how would it feel?" and "If your heart were the weather, how would it feel?" (self-rated health assessment tool). We further classified the questions according to the duration of each symptom-"not persisting for two weeks" and "persisting for two weeks or longer"-based on the Diagnostic and Statistical Manual of Mental Disorders-Fifth Edition depression criteria [28], where five or more symptoms, including depressive mood or loss of interest or pleasure, persisting for two weeks or longer, are required for diagnosis. Furthermore, in the domain of self-rated physical health, we asked the children to describe the body part responsible for and the reason for their condition. In the domain of self-rated mental health, we asked them to identify the cause by circling "school," "home," or "other" and to describe the reason for the marked cause.

Depression assessment was based on Murata et al.'s [17] Japanese version of the Depression Self-Rating Scale for Children (DSRSC) originally developed by Birleson [29]. The 18 statements, designed to examine students' tendencies related to spiritlessness and depression over the past week, were rated on a three-point scale: "Most of the time" (2), "Sometimes" (1), and "Never" (0). The full score is 36 , and the cutoff score is 16 . Higher scores indicate more markedly depressive states. Firth and Chaplin [30] demonstrated that the DSRS-C is useful for screening for depressive states. As there are only 18 statements, the scale does not take much time to complete; therefore, there is not much of a burden on elementary and junior/senior high school students. Statements are easy to understand, with soft expressions to avoid causing mental conflict in participating children.

\section{Ethical considerations}

We visited each of the 13 schools and explained the study objective, methods, and privacy protection measures to receive their consent individually. We asked the school principals to provide parents with this explanation and seek their approval. Subsequently, we asked the homeroom teachers and assistants in charge of distributing the questionnaire to orally explain certain measures to the students to obtain their consent prior to the study. Students were informed that they would not be at any disadvantage for refusing to participate or being unable to complete the questionnaire. It was clarified that all information would be anonymized to prevent the identification of individuals; there would be no pressure on students, the teacher, assistant teacher-in-charge, or others when filling out the questionnaire; students did not need to fill out the questionnaire in front of the teacher; and the statistical processing of all survey results and their use was for this study only. Submitting a questionnaire was regarded as consent from a child. The study was approved by the Medical Ethics Committee of our institution.

\section{Analysis}

To clarify overall associations regarding self-rated health and mean DSRS-C score, we performed an ANOVA based on sex and school type. Subsequently, to clarify the relationship between self-rated health and depressive states, we calculated correlation coefficients adjusted for school type and sex.

For the questionnaire, we regarded "Normal" as a positive answer, thus dividing all answers into two choices: "Good/Relatively good/Normal" and "Relatively bad/Bad" [31]. We then divided the children's ratings of their physical health condition as "Relatively bad/Bad" into two groups based on duration, "not persisting for two weeks" and "persisting for two weeks or longer," and performed an ANOVA. We similarly analyzed data for the domain of self-rated mental health. We performed all analyses using SPSS ver. 26 (IBM Japan, Ltd.). 
Results

\section{Children's self-rated health}

The results of the sex-and school type-based analysis of the self-rated physical and mental health of elementary, junior high, and senior high school students are shown in Tables 1 and 2.

Table 1

Sex- and school type-based analysis of students' self-rated physical health

\begin{tabular}{|c|c|c|c|c|c|c|c|c|c|c|c|}
\hline School & Sex & $n$ & Mean & & $S D$ & $P^{a}$ & Mean & & $S D$ & $\begin{array}{l}\text { One-way } \\
\text { ANOVA }\end{array}$ & Significance \\
\hline \multirow[t]{2}{*}{ Elementary } & Boys & 830 & 3.96 & \pm & 1.08 & \multirow[t]{2}{*}{0.408} & \multirow[t]{2}{*}{3.92} & \multirow[t]{2}{*}{ \pm} & \multirow[t]{2}{*}{1.06} & & \multirow{3}{*}{$\begin{array}{l}\text { Elementary vs Junior High }< \\
0.001 \\
\text { Elementary vs Senior High }< \\
0.001\end{array}$} \\
\hline & Girls & 762 & 3.86 & \pm & 1.04 & & & & & * & \\
\hline \multirow{2}{*}{$\begin{array}{l}\text { Junior } \\
\text { High }\end{array}$} & Boys & 958 & 3.68 & \pm & 1.08 & \multirow[t]{2}{*}{0.095} & \multirow[t]{2}{*}{3.62} & \multirow[t]{2}{*}{ \pm} & \multirow[t]{2}{*}{1.07} & $<0.001$ & \\
\hline & Girls & 917 & 3.56 & \pm & 1.06 & & & & & & \multirow[t]{3}{*}{$\begin{array}{l}\text { Junior High vs Senior High } \\
<0.001\end{array}$} \\
\hline \multirow{2}{*}{$\begin{array}{l}\text { Senior } \\
\text { High }\end{array}$} & Boys & 1036 & 3.38 & \pm & 1.03 & \multirow[t]{2}{*}{0.867} & \multirow[t]{2}{*}{3.36} & \multirow[t]{2}{*}{ \pm} & \multirow[t]{2}{*}{0.97} & & \\
\hline & Girls & 1138 & 3.33 & \pm & 0.92 & & & & & & \\
\hline \multirow[t]{2}{*}{ Total } & Boys & 2824 & 3.66 & \pm & 1.09 & \multirow{2}{*}{$\dot{0} 001$} & \multirow[t]{2}{*}{3.60} & \multirow[t]{2}{*}{ \pm} & \multirow[t]{2}{*}{1.06} & & \\
\hline & Girls & 2817 & 3.55 & \pm & 1.02 & & & & & & \\
\hline \multicolumn{12}{|c|}{ SD: standard deviation } \\
\hline \multicolumn{12}{|c|}{${ }^{a}$ Differences between boys and girls were analyzed using a $t$-test } \\
\hline \multicolumn{12}{|c|}{ Tukey's multiple comparisons } \\
\hline \multicolumn{12}{|c|}{ All data are presented as mean $\pm S D$; one-way ANOVA with post hoc Tukey test was applied for significance testing. } \\
\hline \multicolumn{12}{|c|}{$p$ value is significant at $<0.05$} \\
\hline
\end{tabular}


Table 2

Sex- and school type-based analysis of students' self-rated mental health

\begin{tabular}{|c|c|c|c|c|c|c|c|c|c|c|c|}
\hline School & Sex & $n$ & Mean & & $S D$ & $P^{a}$ & Mean & & $S D$ & $\begin{array}{l}\text { One-way } \\
\text { ANOVA }\end{array}$ & Significance \\
\hline \multirow[t]{2}{*}{ Elementary } & Boys & 830 & 4.00 & \pm & 1.14 & \multirow{2}{*}{$\begin{array}{l}> \\
0.999\end{array}$} & \multirow[t]{2}{*}{3.99} & \multirow[t]{2}{*}{ \pm} & \multirow[t]{2}{*}{1.11} & & $\begin{array}{l}\text { Elementary vs Junior High }< \\
0.001\end{array}$ \\
\hline & Girls & 762 & 3.99 & \pm & 1.08 & & & & & * & \\
\hline \multirow{2}{*}{$\begin{array}{l}\text { Junior } \\
\text { High }\end{array}$} & Boys & 958 & 3.83 & \pm & 1.10 & \multirow{2}{*}{$<.001$} & \multirow[t]{2}{*}{3.69} & \multirow[t]{2}{*}{ \pm} & \multirow[t]{2}{*}{1.12} & \multirow[t]{4}{*}{$<0.001$} & 0.001 \\
\hline & Girls & 917 & 3.54 & \pm & 1.13 & & & & & & $\begin{array}{l}\text { Junior High vs Senior High } \\
<0.001\end{array}$ \\
\hline \multirow{2}{*}{$\begin{array}{l}\text { Senior } \\
\text { High }\end{array}$} & Boys & 1036 & 3.40 & \pm & 1.05 & \multirow[t]{2}{*}{0.336} & \multirow[t]{2}{*}{3.35} & \multirow[t]{2}{*}{ \pm} & \multirow[t]{2}{*}{1.02} & & \\
\hline & Girls & 1138 & 3.31 & \pm & 0.99 & & & & & & \\
\hline \multirow[t]{2}{*}{ Total } & Boys & 2824 & 3.72 & \pm & 1.12 & \multirow{2}{*}{$<.001$} & \multirow[t]{2}{*}{3.65} & \multirow[t]{2}{*}{ \pm} & \multirow[t]{2}{*}{1.11} & & \\
\hline & Girls & 2817 & 3.57 & \pm & 1.10 & & & & & & \\
\hline \multicolumn{12}{|c|}{ SD: standard deviation } \\
\hline \multicolumn{12}{|c|}{ 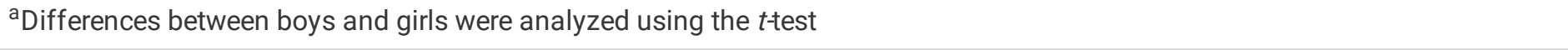 } \\
\hline \multicolumn{12}{|c|}{ Tukey's multiple comparisons } \\
\hline \multicolumn{12}{|c|}{ All data are presented as mean $\pm S D$; one-way ANOVA with post hoc Tukey test was applied for significance testing. } \\
\hline \multicolumn{12}{|c|}{$p$ value is significant at $<0.05$} \\
\hline
\end{tabular}

The overall mean \pm standard deviation score for self-rated physical health was $3.60 \pm 1.06$, and males had significantly higher scores than females. Sex based differences were not observed for any school type. Elementary school students had significantly higher scores than junior and senior high school students, and scores of junior high school students were significantly higher than those of senior high school students. Similarly, the overall mean \pm standard deviation score for self-rated mental health was $3.65 \pm 1.11$, and males had significantly higher scores than females. As for sex based differences at each type of school, males had significantly higher scores than females at junior high schools. Elementary school students had significantly higher scores than junior and senior high school students, and the scores of junior high school students were significantly higher than those of senior high school students.

\section{Depression}

The total DSRS-C scores, representing depression, and the results of the sex- and school type-based analysis of responses to the DSRS-C are shown in Table 3. 
Table 3

DSRS-C scores and sex- and school type-based analysis of responses

\begin{tabular}{|c|c|c|c|c|c|c|c|c|c|c|c|}
\hline School & Sex & $n$ & Mean & & $S D$ & $P^{a}$ & Mean & & $S D$ & $\begin{array}{l}\text { One-way } \\
\text { ANOVA }\end{array}$ & Significance \\
\hline \multirow[t]{2}{*}{ Elementary } & Boys & 830 & 10.79 & \pm & 5.82 & \multirow[t]{2}{*}{0.959} & \multirow[t]{2}{*}{10.91} & \multirow[t]{2}{*}{ \pm} & \multirow[t]{2}{*}{5.90} & \multirow[t]{2}{*}{ * } & \multirow{3}{*}{$\begin{array}{l}\text { Elementary vs Junior High } \\
=0.571 \\
\text { Elementary vs Senior High } \\
0.001\end{array}$} \\
\hline & Girls & 762 & 11.05 & \pm & 5.99 & & & & & & \\
\hline \multirow{2}{*}{$\begin{array}{l}\text { Junior } \\
\text { High }\end{array}$} & Boys & 958 & 10.40 & \pm & 6.28 & \multirow{2}{*}{$<.001$} & \multirow[t]{2}{*}{11.19} & \multirow[t]{2}{*}{ \pm} & \multirow[t]{2}{*}{6.67} & \multirow[t]{4}{*}{$<0.001$} & \\
\hline & Girls & 917 & 12.02 & \pm & 6.96 & & & & & & $\begin{array}{l}\text { Junior High vs Senior High } \\
<0.001\end{array}$ \\
\hline \multirow{2}{*}{$\begin{array}{l}\text { Senior } \\
\text { High }\end{array}$} & Boys & 1036 & 12.76 & \pm & 5.66 & \multirow[t]{2}{*}{0.421} & \multirow[t]{2}{*}{13.02} & \multirow[t]{2}{*}{ \pm} & \multirow[t]{2}{*}{5.91} & & \\
\hline & Girls & 1138 & 13.26 & \pm & 6.12 & & & & & & \\
\hline \multirow[t]{2}{*}{ Total } & Boys & 2824 & 11.38 & \pm & 6.02 & \multirow{2}{*}{$\begin{array}{l}< \\
0.001\end{array}$} & \multirow[t]{2}{*}{11.82} & \multirow[t]{2}{*}{ \pm} & \multirow[t]{2}{*}{6.24} & & \\
\hline & Girls & 2817 & 12.26 & \pm & 6.43 & & & & & & \\
\hline \multicolumn{12}{|c|}{ SD: standard deviation } \\
\hline \multicolumn{12}{|c|}{${ }^{a}$ Differences between boys and girls were analyzed using the $t$ test } \\
\hline \multicolumn{12}{|c|}{ Tukey's multiple comparisons } \\
\hline \multicolumn{12}{|c|}{ All data are presented as mean $\pm S D$; one-way ANOVA with post hoc Tukey test was applied for significance testing. } \\
\hline \multicolumn{12}{|c|}{$p$ value is significant at $<0.05$} \\
\hline
\end{tabular}

The overall mean \pm standard deviation DSRS-C score was $11.82 \pm 6.24$, and females had significantly higher scores than males. As for sex based differences for each type of school, females had significantly higher scores than males in junior high schools. Senior high school students had significantly higher scores than elementary and junior high school students.

\section{Relationship between self-rated health and depression}

Children's depressive states may vary depending on their self-rated health levels. Therefore, to examine the relationships of self-rated physical and mental health scores with total DSRS-C score, we calculated Pearson's and partial correlation coefficients (Table 4).

The correlation coefficients in all cases were significant, ranging from 0.40 to 0.60 .

Table 4

Partial correlation coefficients between children's self-rated physical health, mental health, and DSRS-C

\begin{tabular}{|c|c|c|c|}
\hline & Self-rated physical health & Self-rated mental health & DSRS-C scores \\
\hline \multicolumn{4}{|l|}{ Self-rated physical health } \\
\hline Self-rated mental health & 0.468 & & \\
\hline DSRS-C & -0.446 & -0.583 & \\
\hline
\end{tabular}

DSRS-C, Depression Self-Rating Scale for Children

\section{Effective use of the tool and the relationship between self-rated health and depression risk}

To provide a basis for the effective use of the self-rated health assessment tool, we compared the three groups of children based on their physical/mental conditions together with the duration of those conditions (Favorable Health: rating their physical/mental health condition as "Good/Relatively good/Normal"; Temporarily Poor Health: "Relatively bad/Bad" + "not persisting for two weeks"; and Persistently Poor Health: "Relatively bad/Bad" + "persisting for two weeks or longer"). 
In the domain of self-rated physical health, $85.3 \%$ of all children belonged to the Favorable Health group, whereas those belonging to the Temporarily and Persistently Poor Health groups accounted for $8.1 \%$ and $6.6 \%$, respectively. There were significant differences related to school type, but no sex based differences were observed. In the domain of self-rated mental health, $85.7 \%$ of all children belonged to the Favorable Health group, whereas those belonging to the Temporarily and Persistently Poor Health groups accounted for $5.4 \%$ and $8.9 \%$, respectively. There were significant differences related to both sex and school type (Table 5).

Next, we compared the prevalence of depression among the three groups. In the domain of self-rated physical health, the mean DSRS-C score for each group was as follows: Favorable Health: $11.11 \pm 5.92$, Temporarily Poor Health: $14.71 \pm 6.12$, and Persistently Poor Health: $17.36 \pm 6.68$. The Persistently Poor Health group had significantly higher DSRS-C scores than the Temporarily Poor and Favorable Health groups, while the scores for the Temporarily Poor Health group were significantly higher than those for the Favorable Health group. Similarly, in the domain of self-rated mental health, the mean DSRS-C score for each group was as follows: Favorable Health: $10.77 \pm 5.61$, Temporarily Poor Health: $16.50 \pm 5.81$, and Persistently Poor Health: $19.09 \pm 6.12$. The Persistently Poor Health group had significantly higher scores than the Temporarily Poor and Favorable Health groups, while the scores for the Temporarily Poor Health group were significantly higher than those for the Favorable Health group. As for the DSRS-C cutoff (16), the Persistently Poor Health group had higher self-rated physical health scores, and the Temporarily Poor Health and Persistently Poor Health groups had higher self-rated mental health scores (Tables 6 and 7).

Table 5

Sex- and school type-based analysis of self-rated physical and mental health of school students

\section{Self-rated physical health}

\section{Self-rated mental health}

\begin{tabular}{|c|c|c|c|c|c|c|c|c|c|c|c|c|c|c|}
\hline \multirow[b]{2}{*}{$P$} & \multicolumn{2}{|c|}{$\begin{array}{l}\text { Favorable } \\
\text { Health }\end{array}$} & \multicolumn{2}{|c|}{$\begin{array}{l}\text { Temporarily } \\
\text { Poor Health }\end{array}$} & \multicolumn{3}{|c|}{$\begin{array}{l}\text { Persistently } \\
\text { Poor Health }\end{array}$} & \multicolumn{2}{|c|}{$\begin{array}{l}\text { Favorable } \\
\text { Health }\end{array}$} & \multicolumn{2}{|c|}{$\begin{array}{l}\text { Temporarily } \\
\text { Poor Health }\end{array}$} & \multicolumn{2}{|c|}{$\begin{array}{l}\text { Persistently } \\
\text { Poor Health }\end{array}$} & \\
\hline & $P$ & & & & & & & & & & & & & \\
\hline School & $\mathrm{n}$ & $\%$ & $\mathrm{n}$ & $\%$ & $\mathrm{n}$ & $\%$ & & $\mathrm{n}$ & $\%$ & $\mathrm{n}$ & $\%$ & $\mathrm{n}$ & $\%$ & \\
\hline Elementary & 1417 & $89.0 \%$ & 110 & $6.9 \%$ & 65 & $4.1 \%$ & \multirow{3}{*}{$\begin{array}{l}< \\
0.001\end{array}$} & 1435 & $90.1 \%$ & 74 & $4.6 \%$ & 83 & $5.2 \%$ & \multirow{3}{*}{$\begin{array}{l}< \\
0.001\end{array}$} \\
\hline $\begin{array}{l}\text { Junior } \\
\text { High }\end{array}$ & 1588 & $84.7 \%$ & 136 & $7.3 \%$ & 151 & $8.1 \%$ & & 1601 & $85.4 \%$ & 98 & $5.2 \%$ & 176 & $9.4 \%$ & \\
\hline $\begin{array}{l}\text { Senior } \\
\text { High }\end{array}$ & 1806 & $83.1 \%$ & 210 & $9.7 \%$ & 158 & $7.3 \%$ & & 1799 & $82.8 \%$ & 132 & $6.1 \%$ & 243 & $11.2 \%$ & \\
\hline Boys & 2408 & $85.3 \%$ & 233 & $8.3 \%$ & 183 & $6.5 \%$ & \multirow[t]{2}{*}{0.824} & 2466 & $87.3 \%$ & 142 & $5.0 \%$ & 216 & $7.6 \%$ & \multirow[t]{2}{*}{0.001} \\
\hline Girls & 2403 & $85.3 \%$ & 223 & $7.9 \%$ & 191 & $6.8 \%$ & & 2369 & $84.1 \%$ & 162 & $5.8 \%$ & 286 & $10.2 \%$ & \\
\hline Total & 4811 & $85.3 \%$ & 456 & $8.1 \%$ & 374 & $6.6 \%$ & $\begin{array}{l}< \\
0.001\end{array}$ & 4835 & $85.7 \%$ & 304 & $5.4 \%$ & 502 & $8.9 \%$ & $\begin{array}{l}< \\
0.001\end{array}$ \\
\hline
\end{tabular}

Table 6

Self-rated physical health of DSRS-C scores between the three groups

\begin{tabular}{|c|c|c|c|c|c|c|c|c|c|c|}
\hline \multicolumn{11}{|c|}{ Self-rated physical health } \\
\hline \multirow[t]{4}{*}{ DSRS-C } & \multirow{2}{*}{\multicolumn{3}{|c|}{$\begin{array}{l}\text { Favorable Health } \\
n=4811\end{array}$}} & \multirow{2}{*}{\multicolumn{3}{|c|}{$\begin{array}{l}\text { Temporarily Poor Health } \\
\mathrm{n}=456\end{array}$}} & \multirow{2}{*}{\multicolumn{3}{|c|}{$\begin{array}{l}\text { Persistently Poor Health } \\
n=374\end{array}$}} & \multirow[t]{4}{*}{$P$} \\
\hline & & & & & & & & & & \\
\hline & Mean & & SD & Mean & & SD & Mean & & SD & \\
\hline & 11.11 & \pm & 5.92 & 14.71 & \pm & 6.12 & 17.36 & \pm & 6.68 & \\
\hline & \multicolumn{9}{|c|}{ Favorable Health $\square$ Temporarily Poor Health $\square$ Persistently Poor Health } & $<0.001$ \\
\hline
\end{tabular}

All data are presented as mean $\pm S D$, one-way ANOVA with post hoc Tukey test was applied for significance testing. 
Table 7

Self-rated mental health of DSRS-C scores between the three groups

\begin{tabular}{|c|c|c|c|c|c|c|c|c|c|}
\hline & \multicolumn{2}{|c|}{$\begin{array}{l}\text { Favorable Health } \\
n=4835\end{array}$} & \multicolumn{3}{|c|}{$\begin{array}{l}\text { Temporarily Poor Health } \\
\mathrm{n}=304\end{array}$} & \multicolumn{3}{|c|}{$\begin{array}{l}\text { Persistently Poor Health } \\
n=502\end{array}$} & $P$ \\
\hline \multirow[t]{3}{*}{ DSRS-C } & Mean & SD & Mean & & SD & Mean & & SD & \\
\hline & $10.77 \pm$ & 5.61 & 16.50 & \pm & 5.81 & 19.09 & \pm & 6.12 & \\
\hline & \multicolumn{8}{|c|}{ Favorable Health $\square$ Temporarily Poor Health $\square$ Persistently Poor Health } & $<0.001$ \\
\hline
\end{tabular}

Variance analysis (one factor and three levels) was performed, and Tukey's method was used for multiple comparisons. All data are presented as mean $\pm S D$; one-way ANOVA with post hoc Tukey test was applied for significance testing.

$p$ value is significant at $<0.05$

When asked about their physical health conditions, many children in the Persistently Poor Health group answered that the body part responsible was their "head" (17.7\%), "abdomen, stomach, intestines" (11.8\%), or "low back, shoulder, neck, whole body (25.1\%)." Common reasons included: "I have abdominal pain," "I have a headache," "I can't sleep," "I have a stiff neck and shoulders," "I often vomit," and "I get tired easily." The leading cause of poor mental health in this group was "school" (58.9\%), followed by "home" (15.8\%), and "other" (including N/A) (25.3\%). The most common reasons included: "I feel tired," "I feel gloomy," "There are many things to worry about," "I care about what other people think," "Stress," "Anxiety," "No fun at all," "Bullying," and "I don't understand what I study." "School" (59.8\%) was the leading cause in the Temporarily Poor Health group as well, followed by "home" (10.8\%), and "other" (including N/A) (29.5\%). There were no significant differences between these groups (Table 8).

Table 8

Leading causes of poor mental health in Temporarily Poor Health and Persistently Poor Health groups

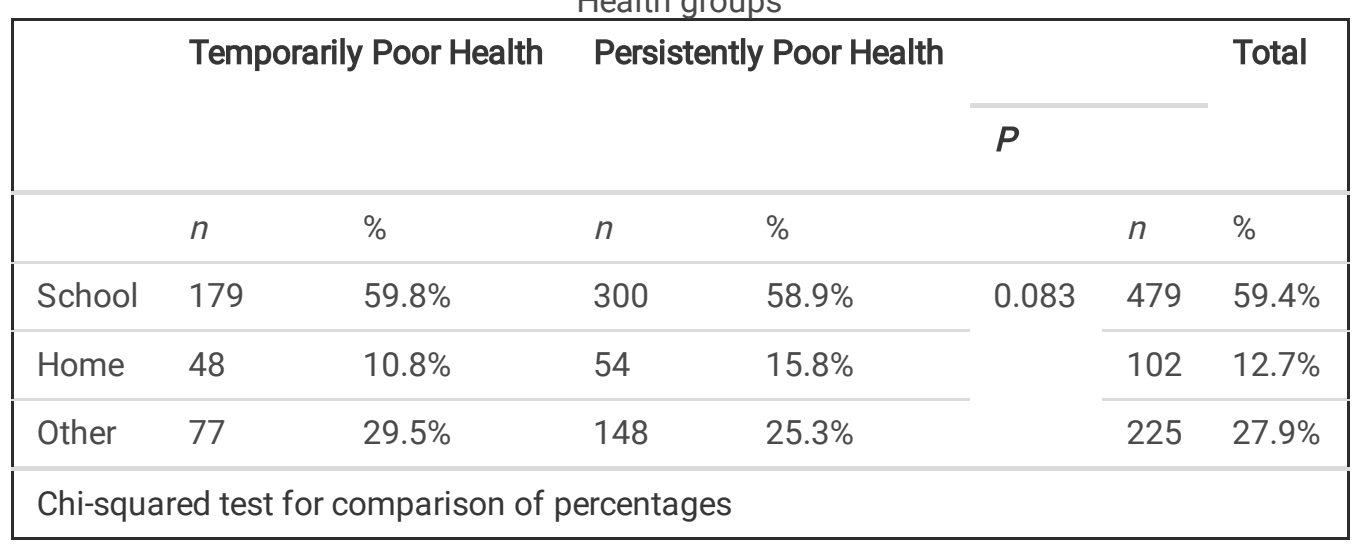

Moreover, to assess the self-rated health screening tool, we calculated sensitivity, specificity, false positive fraction, false negative fraction, prevalence rate, positive predictive value, and negative predictive value by matching with DSRS-C cutoff values (Tables 9 and 10). 
Table 9

Results of self-rated physical health measurements by matching with DSRS-C cutoff values

\begin{tabular}{|llll|}
\hline Self-rated physical health & $\begin{array}{l}\text { Over-16 } \\
\text { Diseased }\end{array}$ & $\begin{array}{l}\text { Under-16 } \\
\text { Disease-free }\end{array}$ & Total $(\boldsymbol{n})$ \\
\hline Screened positive & 226 & 148 & 374 \\
\hline Screened negative & 1329 & 3938 & 5267 \\
\hline Total (n) & 1555 & 4086 & 5641 \\
\hline Sensitivity & $14.5 \%$ & & \\
\hline Specificity & $96.4 \%$ & & \\
\hline False positive fraction & $3.6 \%$ & & \\
\hline False negative fraction & $85.5 \%$ & & \\
\hline Prevalence rate & $27.6 \%$ & & \\
\hline Positive predictive value & $60.4 \%$ & & \\
\hline Negative predictive value & $74.8 \%$ & & \\
\hline
\end{tabular}

Table 10

Results of self-rated mental health measurements by matching with DSRS-C cutoff values

\begin{tabular}{|llll|}
\hline Self-rated mental health & $\begin{array}{l}\text { Over-16 } \\
\text { Diseased }\end{array}$ & $\begin{array}{l}\text { Under-16 } \\
\text { Disease-free }\end{array}$ & Total $(\boldsymbol{n})$ \\
\hline Screened positive & 531 & 275 & 806 \\
\hline Screened negative & 1024 & 3811 & 4835 \\
\hline Total (n) & 1555 & 4086 & 5641 \\
\hline Sensitivity & $34.1 \%$ & & \\
\hline Specificity & $93.3 \%$ & & \\
\hline False positive fraction & $6.7 \%$ & & \\
\hline False negative fraction & $65.9 \%$ & & \\
\hline Prevalence rate & $27.6 \%$ & & \\
\hline Positive predictive value & $65.9 \%$ & & \\
\hline Negative predictive value & $78.8 \%$ & \\
\hline
\end{tabular}

Regarding the results of self-rated physical health measurements obtained by matching with DSRS-C cutoff values, sensitivity was $14.5 \%$, while false negative fraction was $85.5 \%$; however, specificity was $96.4 \%$ and false positive fraction was $3.6 \%$. Therefore, positive results indicated definite depressive states.

Regarding the results of self-rated mental health measurements obtained by matching with DSRS-C cutoff values, sensitivity was $34.1 \%$, false negative fraction was $65.9 \%$, specificity was $93.3 \%$, and false positive fraction was $6.7 \%$. Therefore, positive results indicated definite depressive states.

\section{Discussion}




\section{Relationship between children's self-rated physical/mental health and depression}

In this study, we used an original self-rated health assessment tool for children. In both domains, males' scores were higher than females', and self-rated health levels decreased with age. Depressive states were more prevalent among females than males, and this worsened with age.

Comparisons between the three groups of children-the Favorable, Temporarily Poor, and Persistently Poor Health groups-revealed that the majority of elementary, junior high, and senior high school students lead a physically and mentally healthy school life, as more than $85 \%$ of all children belonged to the Favorable Health group. However, approximately $15 \%$ belonged to the Temporarily or Persistently Poor Health groups, which included those with mania/manic-depressive states, as a symptom of bipolar affective disorder or cyclothymia. Thus, some children may have been experiencing poor mental and physical health.

In the domain of self-rated physical health, children belonging to the Persistently Poor Health group had DSRS-C scores higher than 16 , which is the DSRS-C cutoff, and the "head" and "abdomen, stomach, intestines" were the most common body parts responsible for their poor physical health conditions. Their poor mental health may have been caused by poor physical health; however, the reverse may also be possible. Furthermore, $60 \%$ of them selected "school" as the cause of their poor mental health conditions, suggesting a significant correlation between their psychophysiological symptoms and difficult relationships with school friends, worries about academic achievement, study pressure, and conflicts with parents and teachers [24]. The presence of chronic headaches may also suggest a typical psychophysiological disorder strongly correlated with school dislike [27]. In the domain of self-rated mental health, it should be noted that not only the Persistently Poor Health group but also the Temporarily Poor Health group had scores higher than the DSRS-C cutoff of 16 . Specifically, the mean DSRS-C score in the Persistently Poor Health group was 19 , significantly exceeding the cutoff value and indicating the necessity of early intervention. Furthermore, as more than half of the children selected "school" as the cause of their poor condition, the possibility of schools, where children spend most of their time, causing psychophysiological and depressive symptoms owing to difficulties related to studies, conflict in interpersonal relationships, and poor adaptation to school culture, is undeniable.

Younger children are particularly subject to physical deconditioning. In this study, the reasons for poor physical health conditions such as "I can't sleep" and "I get tired easily" suggest sleeplessness and fatigue. Sleeplessness may indicate depression symptoms and pain such as headaches and stomachaches, whereas general malaise suggests the presence of psychophysiological disorders [25]. These conditions are difficult to screen for only through self-rated mental health assessment. Therefore, when assessing children, it may be necessary to address both physical and mental health.

\section{Effective use of the self-rated health assessment tool to promote collaboration between medical and educational organizations}

When using the self-rated health assessment tool, it may be effective to focus on the Persistently Poor Health group in the domain of physical health and both the Temporarily and Persistently Poor Health groups in the domain of mental health, and provide early intervention to prevent suicide.

By matching with the DSRS-C, it was determined that both the physical and mental health assessments had high specificity and low sensitivity. Generally, screening tests with high sensitivity and specificity are desirable. Tests with high sensitivity are of particular significance to diagnoses of exclusion.

Based on our analyses, we emphasize the need for screening tests with a high degree of specificity. First, trusting, cooperative relationships between those involved in education and medical care are indispensable. Medical and educational professionals are extremely busy. Therefore, when attempting to form a seamless connection between educational and medical care, for adequate treatment to be a possibility, there should be no room for doubt about a child's symptoms. If sensitivity of a test is high and false positives are very common, there is no guarantee that adequate treatment will be received. Moreover, even if a child receives the necessary treatment, false positives may cause those involved in medical care to lose trust in educational institutions.

Second, when connecting children from educational institutions to medical care, it is necessary to have a relationship of trust with parents. If a test with high sensitivity results in false positives and children are consequently connected to medical care, parents will lose trust in teachers. Therefore, it is considered necessary to communicate the screening test results to the concerned individual

Page $11 / 15$ 
and his/her guardian with confidence, and to be very certain about the decision to connect to medical care. A survey on the mental health conditions of elementary and junior high school students revealed a gap between the results of an assessment conducted by homeroom teachers and children's actual mental health conditions [7]. As many children selected "school" as the cause of their poor conditions in the present study, the self-rated health assessment tool may be useful for teachers to objectively identify children with an increased risk of suicide and to make a definitive decision about connecting them to medical treatment.

In addition, the tool helps children to objectively understand themselves. Conceptualization of their body/heart as the weather may help them develop objective insight into their physical and mental conditions. With a growing number of people showing signs of depression, there are currently global concerns over increased suicide risk. In such a situation, the tool may be useful not only for teachers and other people around children to recognize their physical and mental conditions but also for children to objectively understand themselves.

\section{Limitations}

Despite the abovementioned strengths, this study has some limitations. The participants were limited to students from elementary, junior high, and senior high schools in three prefectures, rather than throughout Japan. Assessment methods other than a questionnaire survey, such as interviews, could have been considered. We could also have considered the possible influence of assessment time on disorders with diurnal variations, represented by depression and orthostatic disturbance. A future challenge is to further examine methods to effectively use the self-rated health assessment tool and promote organic collaboration with external support institutions. It is especially important to promptly develop systems for appropriate and organic collaboration between educational settings and medical or welfare services.

\section{Conclusions}

As the Temporarily and Persistently Poor Health groups in the domain of physical and mental health are more likely to suffer from depression, it is necessary for schools to ensure timely cooperation with medical institutions.

\section{Abbreviations}

DSRS-C: Depression Self-Rating Scale for Children

\section{Declarations}

Ethics approval and consent to participate: This study was approved by the medical ethics committee of the Faculty of Education, Kochi University (No.2, 2018). All procedures were carried out in accordance with the ethical standards of the institutional ethics committee and the 1964 Helsinki Declaration and its later amendments. Written informed consent was not sought from the participants, as the voluntary completion and return of the questionnaire implied consent.

Consent for publication: Not applicable.

Availability of data and materials: Not applicable.

Competing interests: The authors declare that they have no competing interests.

Funding: This study was supported by JSPS KAKENHI grant numbers JP18H05748 and JP20H01630. The funding body had no role in the design of the study or collection, analysis, and interpretation of data or in writing the manuscript.

Authors' contributions: YN and AF contributed to the conception and design of this study. MO performed the statistical analysis and drafted the manuscript. YN and AF critically reviewed the manuscript and supervised the study process. All authors read and approved the final manuscript.

Acknowledgements: We would like to thank all the participants, our colleagues, and Professor Harumi Katayama from Hamamatsu Medical University who provided us with guidance about a necessary and sufficient method to create a questionnaire for this study. We would also like to thank Editage for English language editing. 


\section{References}

1. Ministry of Health, Labour and Welfare. Chapter 2: White paper on suicide control; Chap. 3: Status of youth suicide. 2020. https://www.mhlw.go.jp/wp/hakusyo/jisatsu/19-2/dl/2-3.pdf. Accessed 26 April 2020.

2. Hoshi T. Kenkoushihyo to QOL [Health indicator: Qualities of life and health care]. Jpn J Health Behav Sci. 1988;3:59-68.

3. Kaplan GA, Camacho T. Perceived health and mortality: a nine-year follow-up of the human population laboratory cohort. Am J Epidemiol. 1983;117(3):292-304. doi:10.1093/oxfordjournals.aje.a113541.

4. Okado J, Hoshi T, Hasegawa A, Takabayashi K, Watanabe T, Fujiwara Y. Shukantekikenkoukan no igakuteki igi to kenkoushien katsudou [Total review of subjective health and its supportive system]. Comprehensive Urban Studies. 2000;73:125-33.

5. Yamamoto H, Fukushima H, Yamada F. Daigakusei no kenkoushindanji ni shukanntekikenkoukan wo toukoto no igi [The significance of questioning subjective health views during medical examinations of university students]. J Jpn Mibyo Syst Assoc. 2009;15:341-4.

6. Sugisawa A, Sugisawa H. Kenkou jikohyouka ni kansuru kenkyuu no tenkai-beikoku no kennkyu jirei wo chuushin ni [Development of research on health self-evaluation: Focusing on U.S. research cases]. In: Sonoda K, editor. Changing paradigms in health. University of Tokyo Press; 1995. pp. 73-83.

7. Okada M, Nakadoi Y, Fujikawa A. 2fundedekiru Kodomono Mentaruherusu Chekkushiito (Children's mental health check sheet that can be done in 2 minutes. Tokyo: Gakuji Press; 2016.

8. Bridge JA, Goldstein TR, Brent DA. Adolescent suicide and suicidal behavior. J Child Psychol Psychiatr. 2006;47(3-4):372-94. doi:10.1111/j.1469-7610.2006.01615.x.

9. Narishige R, Kawashima Y, Saito T, Okubo Y. Jidouãđ»seinenki no jisatsumisuisha no geninãđ»douki ni kansuru kentou [Examination of the causes and motives for suicide attempts in childhood and adolescence]. Jpn J Child Adolesc Psychiatr. 2012;53:46-53.

10. Beautrais AL. Child and young adolescent suicide in New Zealand. Aust New Zeal J Psychiatr. 2001;35(5):647-53. doi:10.1080/0004867010060514.

11. Brent DA, Perper JA, Moritz G, Allman C, Friend A, Roth C, et al. Psychiatric risk factors for adolescent suicide: a case-control study. J Am Acad Child Adolesc Psychiatr. 1993;32(3):521-29. doi:10.1097/00004583-199305000-00006.

12. Shafii M, Steltz-Lenarsky J, Derrick AM, Beckner C, Whittinghill JR. Comorbidity of mental disorders in the post-mortem diagnosis of completed suicide in children and adolescents. J Affect Disord. 1988;15(3):227-33. doi:10.1016/01650327(88)90020-1.

13. Marttunen MJ, Henriksson MM, Aro HM, Heikkinen ME, Isometsä ET, Lönnqvist JK. Suicide among female adolescents: characteristics and comparison with males in the age group 13 to 22 years. J Am Acad Child Adolesc Psychiatr. 1995;34(10):1297-307. doi:10.1097/00004583-199510000-00015.

14. Marttunen MJ, Aro HM, Henriksson MM, Lonnqvist JK. Mental disorders in adolescent suicide. DSM-III-R Axes I and II diagnoses in suicides among 13- to 19-year-olds in Finland. Arch Gen Psychiatr. 1991;48(9):834-39. doi:10.1001/archpsyc.1991.01810330058009.

15. Shaffer D, Gould MS, Fisher P, Trautman P, Moreau M, Kleinman M, et al. Psychiatric diagnosis in child and adolescent suicide. Arch Gen Psychiatr. 1996;53(4):339-48. doi:10.1001/archpsyc.1996.01830040075012.

16. Harrington R. Affective disorders. In: Rutter M, Taylor E, Hersov L, editors. Child and adolescent psychiatry: modern approaches. 3rd ed. Oxford: Blackwell Science; 1994. pp. 330-50.

17. Murata T, Shimizu A, Mori Y, Oushima S. Gakkouni okeru kodomo no utsubyou Birleson no shouniki ustubyousukeeru kara no kentou [Childhood depressive state in the school situation-Consideration from the Birleson's Scale]. Jpn J Psychiatr. 1996;1:131-38.

18. Okada M, Suzue T, Tamura Y, Katayama H, Jitsunari F. Investigation on the rate and state of self-reported depressive symptoms in high school sample of Japanese adolescents: using the Birleson depression self-rating scale for children (DSRS-C). Jpn J Child Adolesc Psychiatr. 2009;50:57-68.

19. Grøholt B, Ekeberg O, Wichstrøm L, Haldorsen T. Suicide among children and younger and older adolescents in Norway: a comparative study. J Am Acad Child Adolesc Psychiatr. 1998;37(5):473-81. doi:10.1097/00004583-199805000-00008. 
20. Gould MS, Greensberg T, Velting DM, Shaffer D. Youth suicide risk and preventive interventions: a review of the past 10 years. J Am Acad Child Adolesc Psychiatr. 2003;42(4):386-405. doi:10.1097/01.CHI.0000046821.95464.CF.

21. Gould MS, Kramer RA. Youth suicide prevention. Suicide Life Threat Behav. 2001;31:6-31.

22. Jacobs D, Walsh BW, McDade M, Pigeon S. Signs of self-injury prevention manual. Wellesley Hills: Screening for Mental Health; 2009.

23. Ministry of Education, Culture, Sports, Science and Technology. How schools should be as a team and future improvement measures. Central Education Council, Ministry of Education. 2015.

https://www.mext.go.jp/b_menu/shingi/chukyo/chukyo0/toushin/_icsFiles/afieldfile/2016/02/05/1365657_00.pdf. Accessed on Febrruary 15,2021.

24. Murberg TA, Bru E. School-related stress and psychosomatic symptoms among Norwegian adolescents. Sch Psychol Int. 2004;25(3):317-32. doi:10.1177/0143034304046904.

25. Takamiya S, Kawamura M, Ishikawa S, Otani K, Uemoto M. Kodomo no mentaruherusu to shinshinshou. [Children's mental health and psychosomatic disorders]. Jpn J Psychosom Med. 2015;55:1323-28.

26. Tanaka H, Tamai H, Terashima S, Takenaka Y, Tanaka T. Psychosocial factors affecting psychosomatic symptoms in Japanese schoolchildren. Pediatr Int. 2000;42(4):354-58. doi:10.1046/j.1442-200x.2000.01243.x.

27. Tanaka H, Terashima S, Borres MP, Thulesius O. Psychosomatic problems and countermeasures in Japanese children and adolescents. BioPsychoSoc Med. 2012;6(1):1-5. doi:10.1186/1751-0759-6-6.

28. American Psychiatric Association. DSM-5: Diagnostic and statistical manual of mental disorders. American Psychiatric Publishing, Inc. Translated by Takahashi. Ohno S Y. Igaku-Shoin Ltd; 2013. p. 155-86.

29. Birleson $P$. The validity of depressive disorder in childhood and the development of a self-rating scale: a research report. J Child Psychol Psychiatr. 1981;22(1):73-88. doi:10.1111/j.1469-7610.1981.tb00533.x.

30. Firth MA, Chaplin L. Research note: the use of the Birleson Depression Scale with a non-clinical sample of boys. J Child Psychol Psychiatr. 1987;28(1):79-85. doi:10.1111/j.1469-7610.1987.tb00653.x.

31. Baba Y, Kondo K. Jseinoroudou to shukanntekikennkoukann - shuugyoukeitai joukyoubetubunnseki [Women's labor and subjective health: an analysis by employment type and situation]. Instit Res Household Econ. 2005;65:51-9.

\section{Figures}

If your body were the weather, how would it feel? Please mark the most appropriate number with a circle.

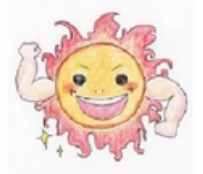

1. Good

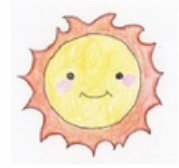

2. Relatively good

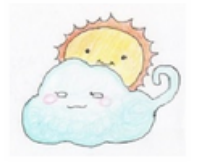

3. Normal

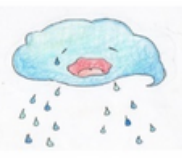

4. Relatively bad

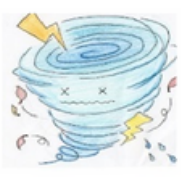

5. Bad

How long has it persisted? (not for 2 weeks, for 2 weeks or longer)

Please mark the appropriate one with a circle.

Please tell me the reason for this.

Parts of the body ( )
[Reason]

\section{Figure 1}

Physical health symptom rating sheet 
If your heart were the weather, how would it feel? Please mark the most appropriate number with a circle.

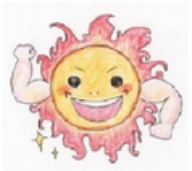

1. Good

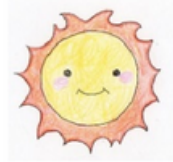

2. Relatively good

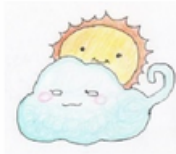

3. Normal

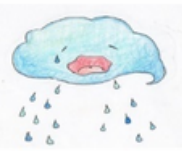

4. Relatively bad

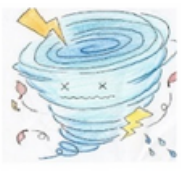

5. Bad

How long has it persisted? (not for 2 weeks, for 2 weeks or longer)

Please mark the appropriate one with a circle.

Please tell me what the cause is.

School, Home, Others

Please mark the appropriate one with a circle

[Reason]

\section{Figure 2}

Mental health symptom rating sheet 